\title{
Empirical Correlations among Liquid Limit, Clay Fraction, and Specific Surface Area for Kaolin and Calcium Bentonite Compounded Samples
}

\author{
Budijanto Widjaja and Claudia Bernadette Inkiriwang
}

\begin{abstract}
Specific surface area (SSA) is one of the engineering properties of clayey soils. This property is highly related to the particle size, strength, compressibility, and permeability of soils. Particle size (i.e., clay fraction) is the most important physical property of clay minerals. Liquid limit (LL), as one of Atterberg's limit, is also an important index to classify fine-grained soils. Kaolinite (non-expansive soils) and calcium bentonite (expansive soils) are selected as primer soils, and $0 \%$ to $40 \%$ sand is added to each soil to reduce clay fraction. These ten representative samples are then tested using the BET method to determine the SSA. The SSA of ten compounded samples of kaolinite and calcium bentonite are in the range of $16.2 \mathrm{~m}^{2} / \mathrm{g}-18.8 \mathrm{~m}^{2} / \mathrm{g}$ and $58 \mathrm{~m}^{2} / \mathrm{g}-69 \mathrm{~m}^{2} / \mathrm{g}$, respectively. Results also show that the increase in clay fraction is accompanied by an increase in the SSA of both kaolin and bentonite. The increase in $L L$ is also accompanied by an increase in SSA. The empirical correlations among LL, clay fraction, and SSA are close to Dolinar and Skrabl's equation.
\end{abstract}

Keywords-BET, clay, calcium bentonite, kaolin, specific surface area, permeability

\section{Introduction}

Specific surface area (SSA) largely determines the engineering properties of clayey soils. This property is highly related to the shear strength, compressibility, and permeability of soils. Liquid limit (LL), as one of Atterberg's limit, and particle size (i.e., clay fraction) are the most important physical properties to classify fine-grained soils. This study determines the empirical correlation among SSA, LL, and clay fraction.

\section{Methods}

Kaolinite (non-expansive soils) and calcium bentonite (expansive soils) were used as primer soils, and $0 \%$ to $40 \%$ sand was added to each soil to reduce clay fraction. Ten representative samples of kaolinite and calcium bentonite (Ca-Bentonite) samples were then tested to determine SSA. As seen in Table 1, the increase in sand content was accompanied by a reduction in both clay fraction and LL.

Budijanto Widjaja

Parahyangan Catholic University

Indonesia

Claudia Bernadette Inkiriwang

Parahyangan Catholic University

Indonesia
As Fig. 1 shows, the SSA based on BET's adsorption isoterm with the gas $\mathrm{N}_{2}$ was determined using a laboratory instrument called surface area analyzer (Quantachrome Instruments-Nova 2000). The LL of kaolinite ranged from 39.15 to 51.90 . The LL of Ca-Bentonite ranged from 56.20 to 93.50. The increase in sand in the mixture of kaolin and sand was accompanied by a reduction in LL.

The clay fraction of kaolinite and Ca-Bentonite was in the range of $29 \%-44.7 \%$ and $13 \%-27 \%$, respectively. The SSA of each compounded sample of kaolinite and CaBentonite was in the range of $16.22 \mathrm{~m}^{2} / \mathrm{g}-18.80 \mathrm{~m}^{2} / \mathrm{g}$ and 58 $\mathrm{m}^{2} / \mathrm{g}-69 \mathrm{~m}^{2} / \mathrm{g}$, respectively.

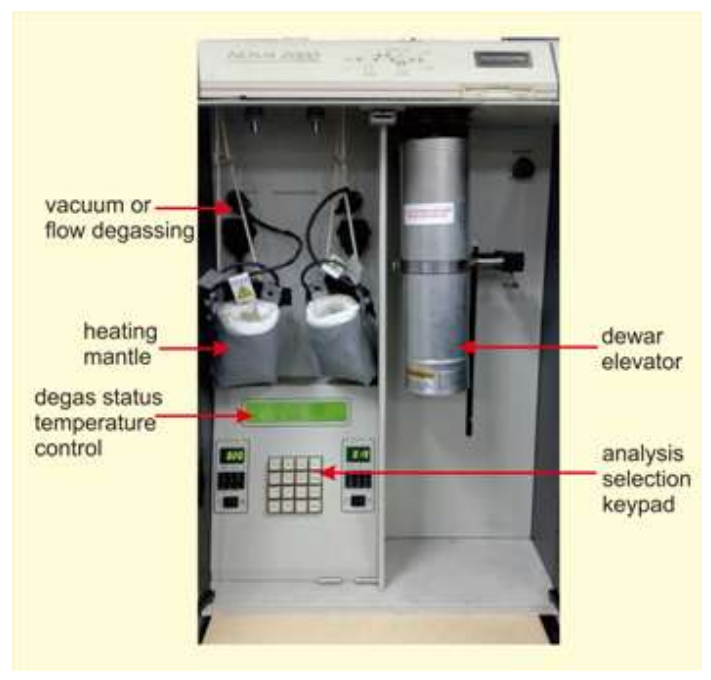

Figure 1. Determination of SSA using BET method.

The activity (A) of kaolinite soils was in the range of 0.12-0.29. According to Ishibashi and Hazarika (2015), kaolinite samples are categorized as inactive soil. However, Ca-Bentonite had an activity in the range of 0.6-0.94. This means that the latest sample was classified as inactive to normal soil.

\section{Result and Discussion}

\section{A. Relationship between LL and SSA}

Fig. 2 shows the relationship between SSA and LL. The increase in LL is accompanied by an increase in SSA. For both kaolinite and $\mathrm{Ca}-\mathrm{Bentonite}$, the proposed empirical equations are as follows:

$$
S S A=0.33 L L+4.33 \text { (for Kaolinite) }
$$




$$
S S A=0.33 L L+38.91 \text { (for Ca-Bentonite) }
$$

As Fig. 2 shows, the SSA of Dolinar and Skrabl (2011) is higher than the results in both Eqs. (1) and (2). This difference may be due to the different types of soil and mineral compositions (Lambe and Whitman, 1969). For example, South African soils (De Bruyn et al., 1957) have higher SSA results than British soils (Farrar and Coleman, 1967) (refer to Fig. 3).

TABLE I. SOILS PARAMETERS

\begin{tabular}{|c|c|c|c|c|c|}
\hline \multicolumn{2}{|r|}{ Sample } & $\begin{array}{c}\text { Liquid } \\
\text { Limit } \\
(L L)\end{array}$ & $\begin{array}{c}\text { Clay } \\
\text { Fraction } \\
(\% \text { Clay }) \\
(\%)\end{array}$ & $\begin{array}{c}\text { Activity } \\
\text { (A) }\end{array}$ & $\begin{array}{c}\text { Specific } \\
\text { Surface } \\
\text { Area } \\
(S S A) \\
\left(\mathrm{m}^{2} / \mathrm{g}\right)\end{array}$ \\
\hline \multirow{5}{*}{ 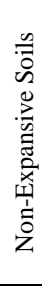 } & $100 \%$ Kaolin & 51.90 & 44.67 & 0.12 & 16.22 \\
\hline & $\begin{array}{c}90 \% \text { Kaolin }+ \\
10 \% \text { Sand }\end{array}$ & 46.80 & 35.80 & 0.18 & 18.70 \\
\hline & $\begin{array}{c}80 \% \text { Kaolin }+ \\
20 \% \text { Sand }\end{array}$ & 43.25 & 34.92 & 0.16 & 17.12 \\
\hline & $\begin{array}{c}\text { 70\% Kaolin }+ \\
\text { 30\% Sand }\end{array}$ & 41.15 & 34.22 & 0.18 & 18.65 \\
\hline & $\begin{array}{c}60 \% \text { Kaolin }+ \\
40 \% \text { Sand } \\
\end{array}$ & 39.50 & 28.96 & 0.29 & 18.80 \\
\hline \multirow{5}{*}{ 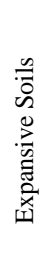 } & $100 \%$ Ca-Bentonite & 93.50 & 27.04 & 0.94 & 69.33 \\
\hline & $\begin{array}{c}90 \% \text { Ca-Bentonite + } \\
10 \% \text { Sand }\end{array}$ & 85.50 & 24.75 & 0.93 & 68.44 \\
\hline & $\begin{array}{c}80 \% \text { Ca-Bentonite + } \\
20 \% \text { Sand }\end{array}$ & 71.80 & 21.37 & 0.75 & 66.41 \\
\hline & $\begin{array}{c}70 \% \text { Ca-Bentonite + } \\
30 \% \text { Sand }\end{array}$ & 67.20 & 20.43 & 0.6 & 58.96 \\
\hline & $\begin{array}{c}60 \% \text { Ca-Bentonite + } \\
40 \% \text { Sand }\end{array}$ & 56.20 & 12.97 & 0.81 & 58.02 \\
\hline
\end{tabular}

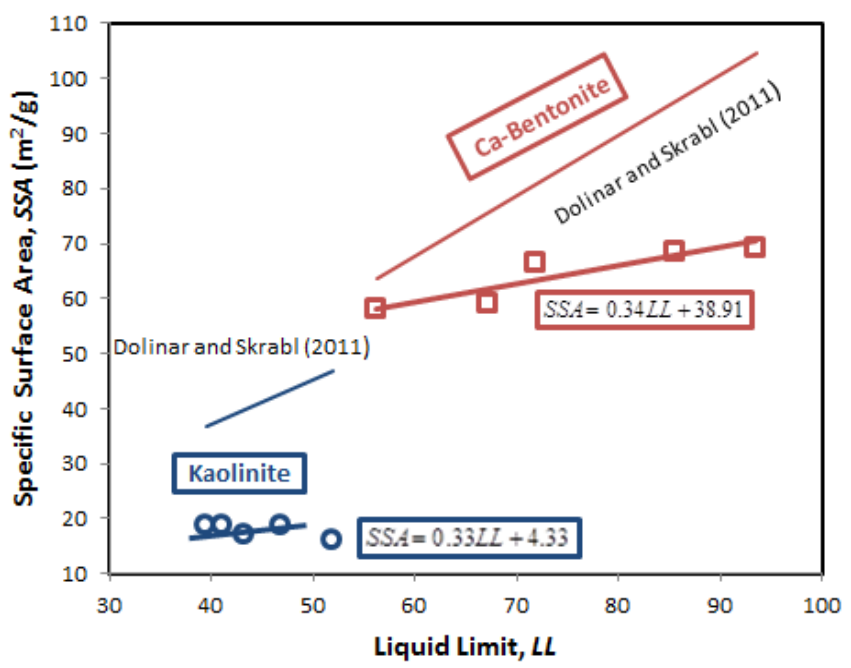

Figure 2. Comparison of Dolinar and Skrabl's method and the test results.

\section{B. Relation between Clay Fraction and SSA}

The relationship between SSA and clay fraction (\%clay) also shows a similar tendency with the previous correlation. The correlations for both soils are as follows:

$$
S S A=0.33(\% \text { clay })+4.33 \text { (for Kaolinite) }
$$

$S S A=1.17(\%$ clay $)+48.33$ (for Ca-Bentonite)

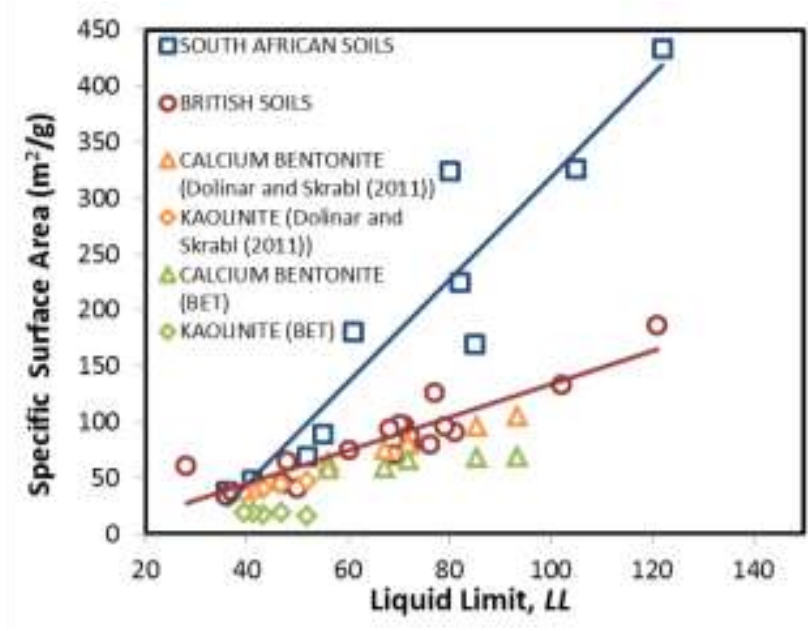

Figure 3. Comparison of SSA and LL from other scholar's results.

As Fig. 4 shows, the correlations are lower than those in Dolinar and Skrabl (2011). Table 2 shows that the reduction of clay fraction is accompanied by a reduction in LL. Hence, the trend between SSA and clay fraction has a proportional result compared with the trend between SSA and LL.

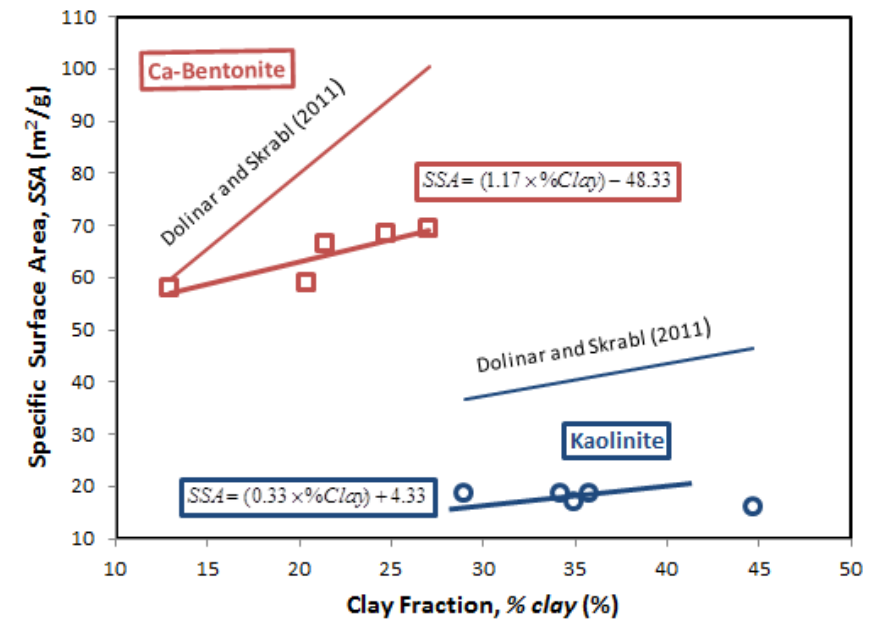

Figure 4. Relationship between clay fraction and SSA.

\section{Relation Between Permeability and SSA at LL}

The Kozeny and Carman method is used to predict the permeability of soil (Kozeny, 1927; Carman, 1939). The equation is as follows:

$$
k=\left(\frac{\gamma}{\eta}\right)\left(\frac{1}{C_{K-C}}\right)\left(\frac{1}{S_{O}^{2}}\right)\left(\frac{e^{3}}{1+e}\right)
$$

where $\gamma$ is the unit weight of water, $\eta$ is the viscosity of water, $C_{K^{-} C}$ is the Kozeny-Carman empirical equation, $S_{0}$ is the SSA per unit volume of particles $(1 / \mathrm{m})$, and $e$ is the void ratio. 
The void ratio for this case is calculated using the specific gravity and water content at LL. The result shows that the permeability $(k)$ of kaolinite soil is between $6.05 \times$ $10^{-14}$ and $2.05 \times 10^{-13} \mathrm{~m} / \mathrm{s}$. The $k$ value of Ca-Bentonite is in the range of $1.74 \times 10^{-14}-3.87 \times 10^{-14} \mathrm{~m} / \mathrm{s}$. This value is close enough to the results of Morris (2003), where $k$ at $L L$ is about $2.5 \times 10^{-13} \mathrm{~m} / \mathrm{s}$. However, the $k$ value of $\mathrm{Ca}-$ Bentonite is about five times smaller than the value suggested by Morris.

For SSA plotted with $k$, the result is shown in Fig. 5. The increase in SSA is accompanied by an increase in the $k$ of kaolinite and $\mathrm{Ca}$-Bentonite. The $k$ value of $\mathrm{Ca}$-Bentonite is smaller than that of kaolinite. This may be due to the different interparticle interactions of kaolinite and bentonite. The increase in the void ratio $(e)$ of $\mathrm{Ca}$-Bentonite may be due to the lower interparticle force. For instance, the $e$ of Ca-Bentonite is 1.4-2.2, and that of kaolinite is 1.1-1.4.

According to Dolinar and Trauner (2004), the quantity of free water depends on the external SSA of kaolinite. However, for $\mathrm{Ca}-\mathrm{Bentonite}$, the quantity of interlayer water is independent of the internal specific surface (i.e., quantity of adsorbed water on the clay surface and quantity of interlayer water) and dependent on the type, quantity of interlayer cations, and chemical composition of pore water (Grim, 1962; Dolinar and Trauner, 2004; Widjaja, 2010).

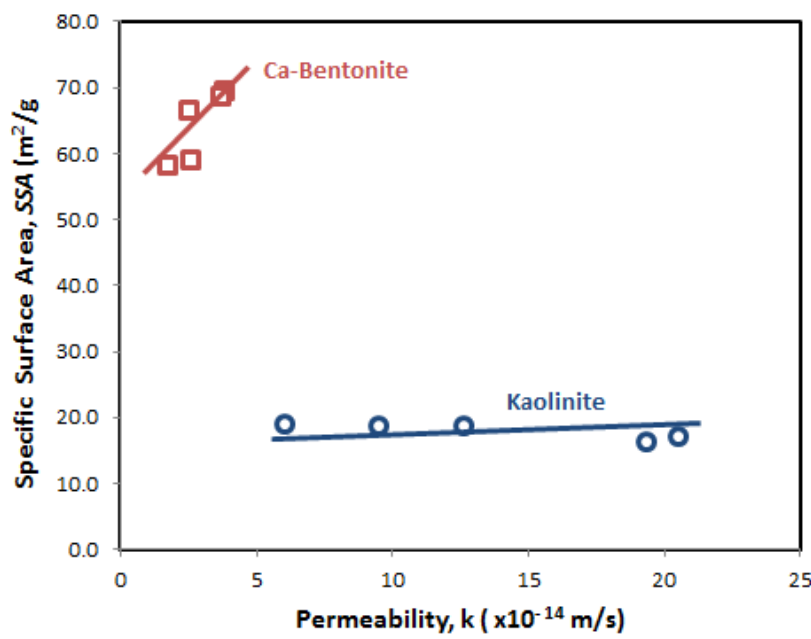

Figure 5. Different trends of the permeability of kaolinite and CaBentonite soils.

\section{Conclusion}

LL and clay content are linearly dependent on the SSA of both kaolinite and Ca-Bentonite. These trends are similar to Dolinar and Skrabl's result. However, the proposed correlation is lower than Dolinar and Skrabl's correlation. This difference may be due to the type and composition of soil minerals.

The permeabilities derived from the Kozeny-Carman equation for kaolinite and $\mathrm{Ca}-B e n t o n i t e$ at water content equal to LL are close to the permeability suggested by Morris. The increase in SSA is accompanied by an increase in permeability. The permeability of Ca-Bentonite is lower than that of kaolinite.

\section{Acknowledgment}

The authors give acknowledgement to Martha Tanziana who prepared the soil laboratory tests in Soil Mechanics Laboratory, Parahyangan Catholic University.

\section{References}

[1] S.M. Aurbach, K.A. Carrado, and P.K. Dutta, Handbook of Layered Materials. NY: Marcel Dekker, Inc., 2004.

[2] M. Budhu, Soil Mechanics and Foundations, $3^{\text {rd }}$ ed.. NY: John Wiley \& Sons, Inc., 2010.

[3] C.M.A. De Bruyn, L.F. Collins, and A.A.B. William, "The specific surface, water affinity, and potential expansiveness of clays," Clay Mineralogy Bulletin, vol. 3, pp. 120-128, 1957.

[4] B. Dolinar and S. Skrabl, "Atterberg limits in relation to other properties of fine-grained soils," Acta Geotechnica Slovenica, vol. 10, no. 2, pp. 4-13, 2013.

[5] B. Dolinar and S. Skrabl, "A simplified method for determining the external specific surface area of non-swelling fine-grained soils," Applied Clay Science, vol. 64, 2011.

[6] B. Dolinar and L. Trauner, "Liquid limit and specific surface of clay particles," Geotechnical Testing Journal, vol. 27, no. 6, pp. 1-5, 2004.

[7] D.M. Farrar and J.D. Coleman, "The correlation of surface area with other properties of nineteen British clay soils," J. Soil Sci., vol. 18, pp. 118-124, 1967.

[8] R.E. Grim, Applied Clay Mineralogy, NY: McGraw Hill, 1962.

[9] I. Ishibashi and H. Hazarika, Soil Mechanics Fundamentals and Applications, $2^{\text {nd }}$ ed. Boca Raton: CRC Press, 2015.

[10] T.W. Lambe and R.V. Whitman, Soil Mechanics. NY: Wiley, 1969.

[11] J.K. Mitchell and K. Soga, Fundamentals of Soil Behaviour, $3^{\text {rd }}$ ed. NY: John Wiley \& Sons, Inc., 2005.

[12] P.H. Morris, "Compressibility and permeability correlations for finegrained dredged materials," Journal of Waterway, Port, Coastal and Ocean Engineering, vol. 129, no. 4, 2003, pp. 188-191.

[13] B. Munhuthan, "Liquid limit and surface area of clays," Geotechnique, vol. 41, no. 1, 1991, pp. 135-138.

[14] B.P. Warkentin, "Use of the liquid limit in characrerizing clay soils," Canadian Journal Soil Science, vol. 95, no. 5, 1972.

[15] B. Widjaja, "Undrained shear strength and compressibility at liquid limit," In Proceedings of The $1^{\text {st }}$ Makassar International Conference on Civil Engineering, 2010.

About Authors:

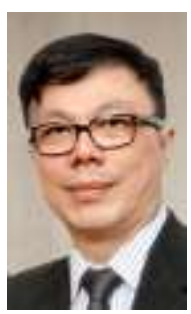

Budijanto Widjaja, Ph.D, has taught soil mechanics and geotechnical engineering at Parahyangan Catholic University, Indonesia. His research interesting is behavior of mudflow, landslides, clayshales, and numerical methods in geotechnical engineering. Nowadays, he is a director of a Center for Geotechnicalhazards $(\mathrm{C} 4 \mathrm{GH})$ and head of Department of Civil Engineering.

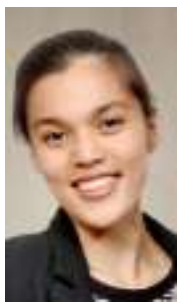

Claudia Bernadette Inkiriwang is a student in Department of Civil Engineering, Parahyangan Catholic University. Her research is soil behavior at plastic and viscous liquid states. She is an engineer staff at Center for Geotehnical-hazards. 